Pautas para ordenar, planificar y gestionar el desarrollo del territorio-ciudad en el área metropolitana de Managua / Guerrero, Napoleón (napoleon.guerrero@gmail.com)

\section{Pautas para ordenar, planifi- car y gestionar el desarrollo del territorio-ciudad en el área metropolitana de Ma-} nagua

\author{
Arq. Napoleón Guerrero \\ Facultad de Arquitectura UNI \\ napoleon.guerrero@gmail.com
}

\section{Reseña}

El texto es una breve reflexión surgida de la observación y recorrido de la ciudad de Managua. Para mejorarlo haría falta una comprobación experimental de las ideas aquí recogidas, es decir cuantificar y medir los aspectos enunciados. Sin embargo, se pretende problematizar sobre estas situaciones para encontrar pautas y recomendaciones que apunte a la elaboración de un modelo viable. Este reconocimiento visual recoge las potencialidades de una ciudad que está en acelerado crecimiento, que tiene muchos espacios de oportunidad y una gran riqueza paisajística.

Las observaciones realizadas ponen en duda algunas nociones fosilizadas en el pensamiento urbanístico de los últimos 60 años, proponen superar estos paradigmas como el dualismo campo-ciudad, la visión desarrollista y crecimiento ilimitado; para situarnos en una perspectiva apoyada en ideas como capacidad de carga del territorio, racionalidad de las nuevas extensiones de la ciudad, clasifica- ción del suelo y límite de suelo urbano; preservación del patrimonio de los suelos de valor natural, productivo y paisajístico; pensamiento propio e identidad cultural.

\section{Palabras claves}

Dualismo urbano-rural, integración, matriz cultural, inmediatismo versus planificación, desarrollo sostenible de Managua.

\section{Planteamiento del trabajo: Territorio- ciudad. Superación del dualismo urbano- rural}

La ciudad es un conjunto de edificaciones y calles dotadas de los servicios de abastecimiento y redes de evacuación, es decir de las infraestructuras básicas para la vida -buena y sana- de una comunidad que está gobernada por una Alcaldía ${ }^{1}$. Comunidad, que no siempre basa el sustento en las actividades agrícolas, según definición del diccionario de la RAE. ${ }^{2}$

La ciudad comprendida como entidad urbana ha sido definida en oposición a lo rural. Sin embargo, entre estos dos niveles contrapuestos existe una interdependencia innegable. El territorio, en cambio es un concepto que comprende tanto el ámbito rural como el urbano. Este es explicado como el lugar concreto donde vive una comunidad que mantiene vínculos de unidad generados por consanguinidad, parentesco o intereses comunes ${ }^{3}$. El territorio es la base-soporte de la matriz natural y la matriz antrópica. Sustenta los asentamientos humanos, espacios agrícolas y de interés natural y patrimonial. El concepto de territorio abarca los componentes artificiales y naturales que componen el paisaje que visualizamos y construimos con nuestra actividad.

1. RAE (2014). Ciudad. (Consultado el 10 de Octubre de 2014). Disponible en Internet: bhttp://lema.rae.es/drae/? val=intenci\%C3\%B3n.

2. Debemos preguntamos si esta definición no ha dejado fuera a las formas de vida de los Pueblos originarios de nuestro continente en los que la ciudad fue entendida como un centro de reunión y celebración de un vasto territorio natural, como lugar donde comparecían el hombre y los dioses. Lugar de la celebración y fiesta.

3. En este sentido de ciudad-territorio, entendemos que estas reflexiones abarcan a los municipios que configuran el área o región metropolitana. El nivel de actividad, tamaño y urbanidad no se mide por la denominación administrativa de los asentamientos humanos, sus problemáticas se inscriben en la necesidad de conseguir el equilibrio entre la matriz natural y antrópica, responder a las necesidades del "desarrollo urbano local" y el compromiso con el principio de sostenibilidad ambiental, orientado desde el Plan Nacional de Desarrollo Humano 20122016. 


\section{Arquitectura + / Año 1- Edición 1 / Junio 2016}

Pautas para ordenar, planificar y gestionar el desarrollo del territorio-ciudad en el área metropolitana de Managua / Guerrero, Napoleón (napoleon.guerrero@gmail.com)

Por otra parte, consideramos que existe la urgencia de superar la dicotomía inconsciente del pensamiento que opone de manera antagónica la ciudad y el territorio abierto. El territorio abierto es concebido como base real de nuestro sustento, productividad y única riqueza patrimonial. A este respecto es innegable que Managua y los municipios que conforman el área metropolitana, en tanto gozan de autonomía municipal, tienen la urgencia de pensar su territorio en términos holísticos y superar la visión dualista, que confronta los territorios rurales con la parte considerada urbana. La situación actual y las tendencias del crecimiento de nuestros territorios y ciudades hace pensar que resulta apremiante un cambio de consciencia y percepción que permita poner en valor los elementos patrimoniales

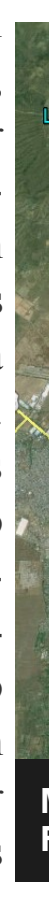

po sereno, definirían aquellos ámbitos que alojan actividades vinculadas a los ritmos de las cosechas, ciclos de la naturaleza -agua, viento, tierra- y movimiento de los astros. Conceptualización que estaría en proximidad con nuestra matriz patrimonial precolombina. Podemos afirmar que desde siempre hemos sido un Pueblo originario que vivió, antes de la colonia, en del territorio y el paisaje,

muchas veces menospreciado como rural o simplemente calificado como rústico o agrícola; como si estos atributos fuesen sinónimos de ámbitos poco desarrollados o con poco dinamismo para el $<$ progreso o crecimiento $>$. ${ }^{4}$

\section{Cultura. Integración de la doble matriz cultural: precolombina y occidental}

También es cierto que hace falta entender que el tiempo transcurre de manera diferente en el territorio rural y el urbano. Los territorios rurales que podemos calificar como portadores de un suceder de tiempo de ti- profunda unidad con su centro espiritual Ometeotl en la región denominada CemAnahuac. Pero también, hemos heredado recientemente desde hace 500 años, la matriz occidental moderna y no podemos escapar a la mentalidad racionalista y la pretendida objetividad de la ciencia y tecnología, ahora en su fase de mundialización. Por tanto es necesario buscar los criterios, principios y elementos para elaborar una nueva cosmovisión, que tiene por tarea conciliar la riqueza de esta cuádruple matriz cultural de raíces precolombinas y occidentales (hispánicas y anglosajonas), y en el nivel geográfico territorial conformada por el estrato urbano y rural.

\section{Necesidad. Superación del inmediatismo, apuesta por la planificación}

Managua y las municipalidades del ámbito metropolitano experimentan necesidades para alcanzar un desarrollo humano adecuado.

4. Progreso y Crecimiento. Dos paradigmas promovidos por la visión moderna, compartidos en algunos casos por la ideología capitalista "desarrollista" y la ideología socialista. Estos conceptos han justificado un crecimiento ilimitado, sin tener en cuenta la capacidad de carga y los límites de los recursos naturales y humanos de un territorio visto como objeto de expoliación inagotable. 


\section{Arquitectura + / Año 1- Edición 1 / Junio 2016}

Pautas para ordenar, planificar y gestionar el desarrollo del territorio-ciudad en el área metropolitana de Managua / Guerrero, Napoleón (napoleon.guerrero@gmail.com)

En cuanto <necesidad> significa impulso que hace que las causas de la situación que vivimos sean irresistibles, podemos entonces deducir que si el cambio de percepción y mente, antes mencionado, sobre la concepción de oposición entre los niveles urbano y rural no se produce, será imposible sustraernos o resistir a la tendencia actual, sobre la cual se precipita de forma poco planificada el desarrollo urbano y rural de nuestro territorio.

Los municipios próximos a Managua, en cuanto son partes del territorio-soporte, necesitan de una herramienta eficaz para planificar, ordenar, regular, controlar y gestionar toda la complejidad del territoriociudad, dirigida a mantener un equilibrio sostenible entre naturaleza y cultura. Para ello es necesario apostar por los principios de la sostenibilidad, apoyarnos en un proyecto orientado al desarrollo humano integral; entender la ciudad y el campo como dos entidades interdependiente que se apoya sobre una misma base territorial y como partes de un organismo vivo llamado GAIA ${ }^{5}$.

Es urgente entonces preguntarnos sobre cuál es la situación de nuestro Territorio-Ciudad en Mangua. Enumerar sus necesidades, observar las dinámicas de crecimiento urbano e interrogarnos:

- ¿Cuál es el modelo de extensión de la ciudad?

- ¿Cómo construimos las nuevas partes de ciudad y bajo qué criterios? y sobre todo evaluar ¿cuáles son los resultados en términos de urbanidad?

- ¿Estamos resolviendo los retos del crecimiento urbano: la necesidad de infraestructuras básicas que hacen la ciudad saludable, la demanda de viviendas dignas? igualmente, ¿estamos respondien- do adecuadamente el riesgo de los desastres naturales?

- ¿Cómo contribuyen las nuevas urbanizaciones a la creación del espacio público?, necesario para generar y propiciar el encuentro entre los ciudada$\operatorname{nos}^{6}$. En el sobre entendido que ser ciudadano implica ser "... Sujeto de derechos políticos y que interviene, ejercitándolos en el gobierno del país."

- En este último caso, podemos preguntarnos: ¿Si, el modelo de las urbanizaciones cerradas es un modelo incluyente y democrático? o tiende más bien a extender el modelo urbano capitalista de ciudad cerrada y estratificada según niveles socioeconómicos y capacidad adquisitiva. La respuesta es obvia. Las consecuencias la encontramos reflejadas en el caos de la movilidad urbana y metropolitana, el colapso del transporte público y privado, el incremento de los desastres por inundación y aluviones, la contaminación del manto freático y otras patologías urbanas, que hacen de la ciudad un no-lugar en el que hay que vivir en situación de desarraigo.

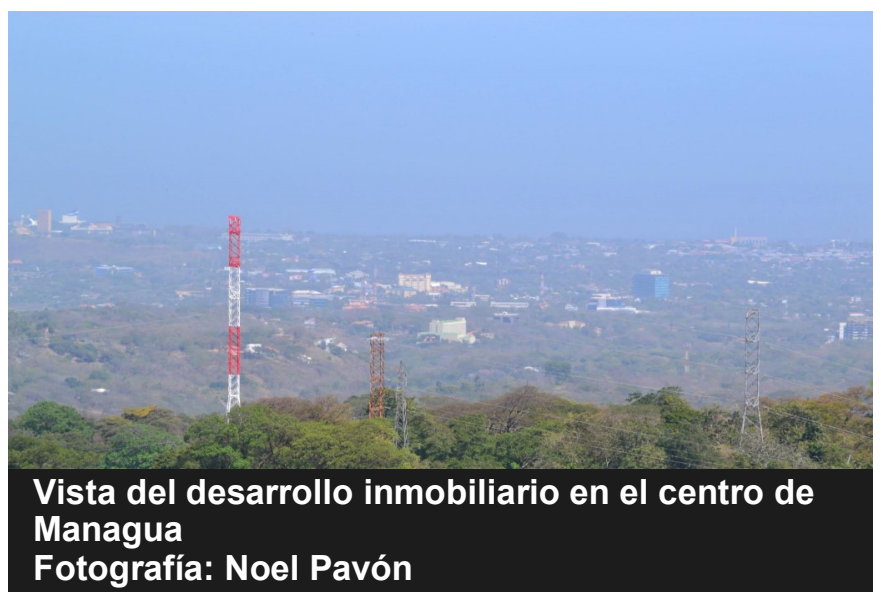

5. Definido como un sistema u organismo vivo del cual el hombre es parte responsable en su equilibrio y supervivencia. Tomado del pensamiento ecologista de Leonardo Boff. Ver: Boff, L. (2014) La opción Tierra. Cantabria: Sal Terrae.

6. RAE. Diccionario de la Real Academia Española. (Consultado 8 de octubre de 2014). En internet: http://lema.rae.es/drae/? val=intenci\%C3\%B3n. 
América Latina, en general enfrenta varias situaciones de patologías urbano-territoriales: ${ }^{7}$

1. El hiper-crecimiento, uso alargado del territorio, megalopolización y sprawl. La urbanización en esta región crece a tasas promedio del 3\% al 4\%.

2. (Carencias de servicios, sub-urbanización, infraurbanización y fragmentación urbana. Estos crecimientos acelerados, en particular en los países más pobres, generan grandes déficits de infraestructura y saneamiento, entre el 50\% y el $90 \%$ de población carece de los mismos, con las consecuencias ambientales negativas para el Buenvivir.

3. Discontinuidad de gestión, crisis de gobernabilidad e inequidad. Típica de los países subdesarrollados, donde a cada periodo electoral sobrevienen cambios y suplantaciones de personal ineficaces.

4. Poca capacidad para proyectar, realizar inversiones, y falta de credibilidad en la planificación. Factores que derivan del modelo económico neoliberal, preocupado principalmente por la coyuntura financiera y la atención de la deuda externa.

5. Inseguridad, segregación social e insolidaridad, fuertemente basada en el modelo económico político mencionado y que promueve como único modelo deseable a la ciudad cerrada. (MALASQUEZ: 2006).
Reseñado este panorama podemos afirmar que en esta ciudad vivimos sin residir en abundancia. Soñando con escapar los fines de semana a lugares más sanos, naturales y con un ritmo más humano. La ciudad se ha convertido en un artefacto que usamos, pero que somos incapaces de habitar en el sentido pleno de la palabra. Habitar significa: estar, quedarse, permanecer en un lugar, residir. En un sentido más integro, habitar implica morar en paz con la comunidad. Para habitar plenamente necesitamos procurarnos una vivienda, lugar en el que vivimos y del que vivimos. La tarea del urbanista, entonces consiste en crear condiciones para que los lugares estén dotados para cumplir las funciones de orientación, significado e identidad. ${ }^{8}$

En definitiva, desde la perspectiva de la disciplina del Urbanismo y la Ordenación del Territorio, existen necesidades y retos a los que responder teniendo en cuenta la situación actual de Managua, tanto a nivel técnico como desde la propia cultural. La respuesta a las necesidades de Managua territoriociudad, requiere previamente de un cambio superación- de paradigmas, y para ello es necesario abrir un debate sobre los contenidos y temas que debería abordar un Plan Urbanístico de Ciudad. La pregunta previa a la formulación de cualquier Plan urbanístico es ¿qué modelo de territorio-ciudad imaginamos como deseable para nuestro pueblo y cultura?

7. Malasquez D, R. (2006). Desarrollo urbano sostenible en América Latina y el Caribe. La agenda pendiente de los gobiernos locales. En: Revista Voxlocalis, $n^{\circ}$ 1. Enero. (Consultado 5 de noviembre de 2014). Disponible en Internet: http:// www.voxlocalis.net/revistas/num1/doc/DESARROLLO\%20URBANO\%20SOSTENIBLE.pdf.

8. Lynch, K. (1970). La imagen de la ciudad. Buenos Aires: Ed. Infinito. 


\section{Arquitectura + / Año 1- Edición 1 / Junio 2016}

Pautas para ordenar, planificar y gestionar el desarrollo del territorio-ciudad en el área metropolitana de Managua / Guerrero, Napoleón (napoleon.guerrero@gmail.com)

\section{Ordenación del Territorio. Recomendacio-} nes y pautas para el desarrollo sostenible

El Plan Urbanístico es el instrumento que permite concretar los sueños y utopía de la ciudad imaginada colectivamente. Entendemos utopía como término que recoge los sueños y aspiraciones de la ciudad. Nunca en el sentido de no-lugar o situación postergada a un tiempo que está más allá y es ultra terreno. Sino más bien en el sentido de impulso o motor de perfección, fuente de esperanza para alcanzar estados de perfección más altos en todo lo que implica la vida en el territorio-ciudad.

Hablaríamos más bien de una topía ${ }^{9}$ en construcción y mejora, un proceso continuo de crecimiento humano colectivo, tanto en el sentido material de la ciudad, como en el sentido de los procesos de convivencia que implica como polis, lugar de muchos y escenario de la política, es decir de las relaciones entre hermanos. El Plan es una herramienta que posibilita prefigurar el modelo de territorio-ciudad que entre todos los actores construimos y concertamos. El Plan en tanto elaboración colectiva y participación implica un proceso pedagógico en el que la población gana conocimiento profundo sobre el patrimonio cultural, natural y paisajístico, propiciando un sentimiento de identidad y arraigo.

A la vez que los mismos habitantes conocen, crean y acuerda las normas y procedimientos para guiar el proceso de desarrollo urbano y rural, desde el crite- rio de prevalencia del bien común y el desarrollo humano integral.

Los profesionales implicados en el proceso de planeamiento, han de superar la aplicación acrítica de los modelos ofrecidos por la urbanística internacional, y la aplicación mecánica de un urbanismo concebido desde el quietismo y la comodidad del simplismo de las normas, que sólo aspiran a regular el crecimiento concebido y aceptado -acaso inconscientemente- como connatural. Como si la ciudad fuese un ente que crece por generación espontánea, sin la reflexión y racionalidad necesaria de toda iniciativa plenamente humana y consciente.

Es necesario partir de un pensamiento propio, arraigado en la cultura y las necesidades de la población y su territorio, que tenga en cuenta las líneas estratégicas y criterios perfilados en el $\mathrm{PNDH}^{10}$ y las demandas visibles de los barrios residenciales. En este sentido, proponemos seis retos para el planeamiento de Managua a escala de territorio y seis retos a escala de ciudad.

Retos para el planeamiento de Managua a escala de territorio:

1. Mejorar el concepto de Clasificación del Suelo adoptado por los Planes Reguladores y que funciona actualmente como herramienta de la planificación a escala nacional, formulado en tres categorías: suelo urbano, suburbano y rural. ${ }^{11}$

\section{En el sentido que Leonardo Boff da a este término.}

10. PNDH. Plan Nacional de Desarrollo Humano 2012-2016. Es necesario retomar las escalas de la Planificación Física de Nicaragua: Planes de escala territorial, regional y municipal. Actualmente, existe una fecunda aparición de instrumentos de planeamiento elaborados desde distintas ópticas (medioambientales y de gestión del riesgo) que deben someterse a la jerarquía de la Ordenación del Territorio para que guarden su economía, eficacia, rigor y universalidad. Resulta urgente y necesaria una Ley General del Suelo.

11. Terminología que no parece establecer con claridad taxativa suficiente los valores morfológicos y normativos de cada uno de estos tres ámbitos de actividad. En contraposición la experiencia del planeamiento urbanístico internacional presenta las categorías de Suelo urbano (consolidado y no consolidado), Suelo urbanizable (programado y no programado) y Suelo no urbanizable. 


\section{Arquitectura + / Año 1- Edición 1/ Junio 2016}

Pautas para ordenar, planificar y gestionar el desarrollo del territorio-ciudad en el área metropolitana de Managua / Guerrero, Napoleón (napoleon.guerrero@gmail.com)

2. Introducir nuevas herramientas en la planificación, ordenamiento y gestión del suelo, (Planes parciales, planes de mejora, planes especiales, modificaciones puntuales, estudios de detalle), buscar la coherencia de estas con los criterios y principios de la ordenación sostenible del territorio, medio ambiente y la previsión del riesgo.

3. Establecer los mecanismos de gestión, protección y preservación de los suelos de alto valor natural y agrícola. (Corredores y conectores ecológicos, parques y zonas de especial protección de la flora y la fauna)

4. Reconocer el funcionamiento a nivel geomorfológico, hídrico e hidrológico del territorio con el objeto de circunscribir las zonas que no son aptas para la ocupación urbana y que están sujetas al riesgo o desastre natural.

5. Reflexionar sobre el modelo de extensión de la ciudad. Sabiendo que el modelo de ciudad compacta frente al modelo de ciudad dispersa, evita el consumo desmedido del suelo agrícola y los suelos de valor natural ${ }^{12} \mathrm{y}$ valor paisajístico.

\section{Retos para el planeamiento de Managua a escala de ciudad:}

6. Dotar los tejidos urbanos (residenciales) de infraestructuras básicas para garantizar una ciudad saludable y un Buen vivir ${ }^{13}$.
7. Responder a la necesidad urgente de soluciones habitacionales dignas, considerando los modos de vidas, producción, cultura y el significado de habitabilidad, de manera que las soluciones habitacionales tengan en consideración los aspectos antropológicos, sociales, económicos y culturales.

8. Formular programas de equipamiento público a escala municipal y de barrio. Tener en cuenta el sentimiento de identidad y pertenencia que estas iniciativas generan, así como el efecto contagio en la mejora de los tejidos residenciales adyacentes.

9. Garantizar el cumplimiento de las cesiones urbanísticas para la consolidación de los Sistemas de Espacios Cívicos y los Sistemas de Equipamientos Comunitarios.

10. Mejorar el espacio público: recuperación de la acera como espacio preferencial del peatón y de las personas que tienen su modo de vida en la calle. Particularmente el ordenamiento espacial y temporal de las actividades del comercio denominado informa ${ }^{14}$, que sigue la lógica de los flujos de desplazamiento y transporte de la ciudad.

12. Los acuíferos del ámbito occidental de Managua son ejemplo de suelos de valor natural, actualmente, amenazados por la contaminación de suelos generada por la infra-urbanización incontrolada.

13. Sumak kawsay (Buen vivir) Concepto que proviene de la cosmovisión de los pueblos originarios (quichuas, aymaras, guaraníes) de América. Este concepto se refiere al ideal de realización del Planeta (Madre-Tierra), que comprende a todas las especies y entre ellas el hombre como responsables del equilibrio entre los recursos naturales y las necesidades humanas. Tomar sólo lo necesario para la vida es una idea que está en confrontación con las ideas modernas de Crecimiento y Progreso ilimitado. Ambas basadas en el paradigma occidental que ve la naturaleza como almacén ilimitado de recursos dispuesto para la explotación. Actitud criticada desde 1927 por la filosofía de Martín Heidegger y Hans Jonas y retomada por el pensamiento ecologista brasileño de Leonardo Boff.

14. En este punto, hace falta una reflexión antropológica profunda, que reconozca las raíces precolombinas de los modos de vida de la población, históricamente dedicadas a la actividad de la agricultura, artesanía y sobre todo al intercambio en los tiangues. La pregunta orientadora puede ser al respecto de la recuperación del espacio necesario para el intercambio. ¿Cómo, la calle un elemento urbano de la ciudad de matriz occidental, prácticamente inexistente en el mundo precolombino -concebida únicamente como camino procesional o ritual en Teotihuacán y en el período postclásico en Tulum-, puede acoger una actividad ancestral, practicada por gran número de personas en la ciudad?. 
Pautas para ordenar, planificar y gestionar el desarrollo del territorio-ciudad en el área metropolitana de Managua / Guerrero, Napoleón (napoleon.guerrero@gmail.com)

11. Ordenar y regular la movilidad y el transporte público como estrategia para mejorar el impacto sobre el consumo energético, y aminorar la contaminación medioambiental. Recuperar la idea de Sistémica sobre la red viaria y el transporte público.

12. Prever y regular los asentamientos humanos espontáneos, trabajar con la idea de un urbanismo progresivo, que deberá prever el completamiento de los tejidos urbanos en la medida de la capacidad económica alcanzada por el tejido social y los propios habitantes. transporte. Además la capital necesita elaborar un proyecto integral de recuperación del frente de costa a orillas del Lago, tema iniciado de manera puntual con las intervenciones del Puerto Salvador Allende y Paseo Xolotlán. También, mejorar las centralidades urbanas de escala distrital y de barrio; plantearse un proyecto articulador del espacio de mayor actividad edilicia y económica que abarca el ámbito de mayor centralidad, que se extiende desde la Catedral nueva hasta Camino de Oriente de Norte a Sur, y desde la rotonda de Metro Centro hasta la del periodista de Este a Oeste.

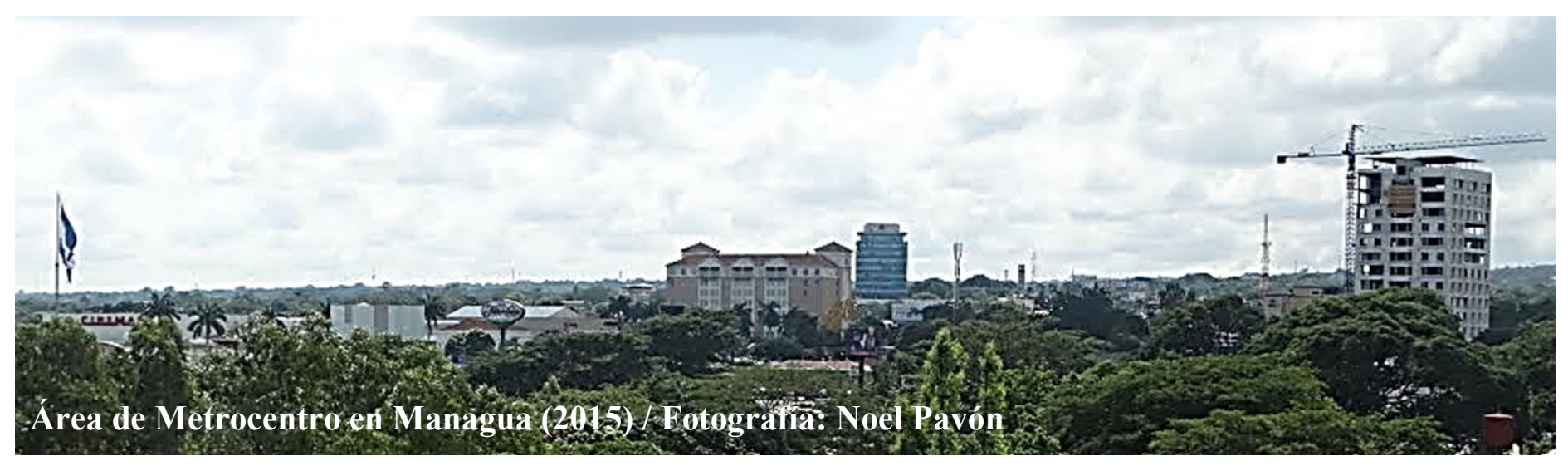

\section{CONCLUSIONES}

Managua en los últimos años está recuperando de manera inaudita el crecimiento urbano estancado por décadas. Crece dejando grandes vacíos urbanos o espacios de oportunidad, que configuran tejidos urbanos inconexos, poco accesibles y desarticulados con su centro histórico. La ciudad parece más un conglomerado de diferentes morfologías y tejidos urbanos pendientes de sutura y continuidad.

Managua necesita urgentemente de la elaboración de un modelo urbano para regular los nuevos crecimientos residenciales. Mejorar las infraestructuras básicas para evitar la contaminación de las aguas, articular los tejidos urbanos. Renovar el espacio público y el sistema de equipamientos comunitarios. Optimizar las vías de circulación y
Para alcanzar estos objetivos, precisamente es necesario señalar la urgencia de un marco legal urbanístico adecuado. Es decir la aprobación de una Ley general de Urbanismo y de Ordenación del territorio, que englobe y sistematice metodologías y procedimientos disciplinares, recientemente multiplicados en nuestro contexto nacional, debido a la adopción de diferentes enfoques y a veces por el inmediatismo de las respuestas ante situaciones de emergencia. 
Pautas para ordenar, planificar y gestionar el desarrollo del territorio-ciudad en el área metropolitana de Managua / Guerrero, Napoleón (napoleon.guerrero@gmail.com)

Inevitablemente este esfuerzo sólo puede ser fruto del respaldo de las instituciones, acompañado de un respaldo económico que lo viabilice, y ratificado en la voluntad política de quienes gobiernan. Para garantizar su éxito deberá estar apoyado en un proceso pedagógico que apunte a crear una cultura de ciudad y territorio, validado por la participación ciudadana. En la que habrán de concurrir todas las fuerzas vivas del territorio. El camino para materializar los sueños de una ciudad pasa por la concertación del modelo urbano, construido entre todos y basado en el bien común.

Finalmente, decir que enunciar estas observaciones en forma de retos y a veces de recomendaciones y pautas, tiene la intención de abrir el debate disciplinar en el que podamos enriquecernos mutuamente, con los conocimientos y experiencias sobre la planificación urbanística y ordenación territorial. También, persigue contribuir a la planificación e investigación urbanística de la ciudad de Managua.

Hoy más que nunca por la dinámica y tendencia latente del desarrollo urbano y rural, necesitamos construir un modelo de ciudad que recoja los sueños $\mathrm{y}$ aspiraciones de sus habitantes y proporcione un camino a seguir en la construcción del territoriociudad, apoyado en la concertación civil y participación ciudadana, único camino para el fortalecimiento de las instituciones del Estado.

\section{FUENTES}

Lynch, K. (1970). La imagen de la ciudad. Buenos Aires: Ed. Infinito.

Boff, L. (2014) La opción Tierra. Cantabria: Sal Terrae.

\section{La arquitectura es el testigo menos so- bornable de la historia}

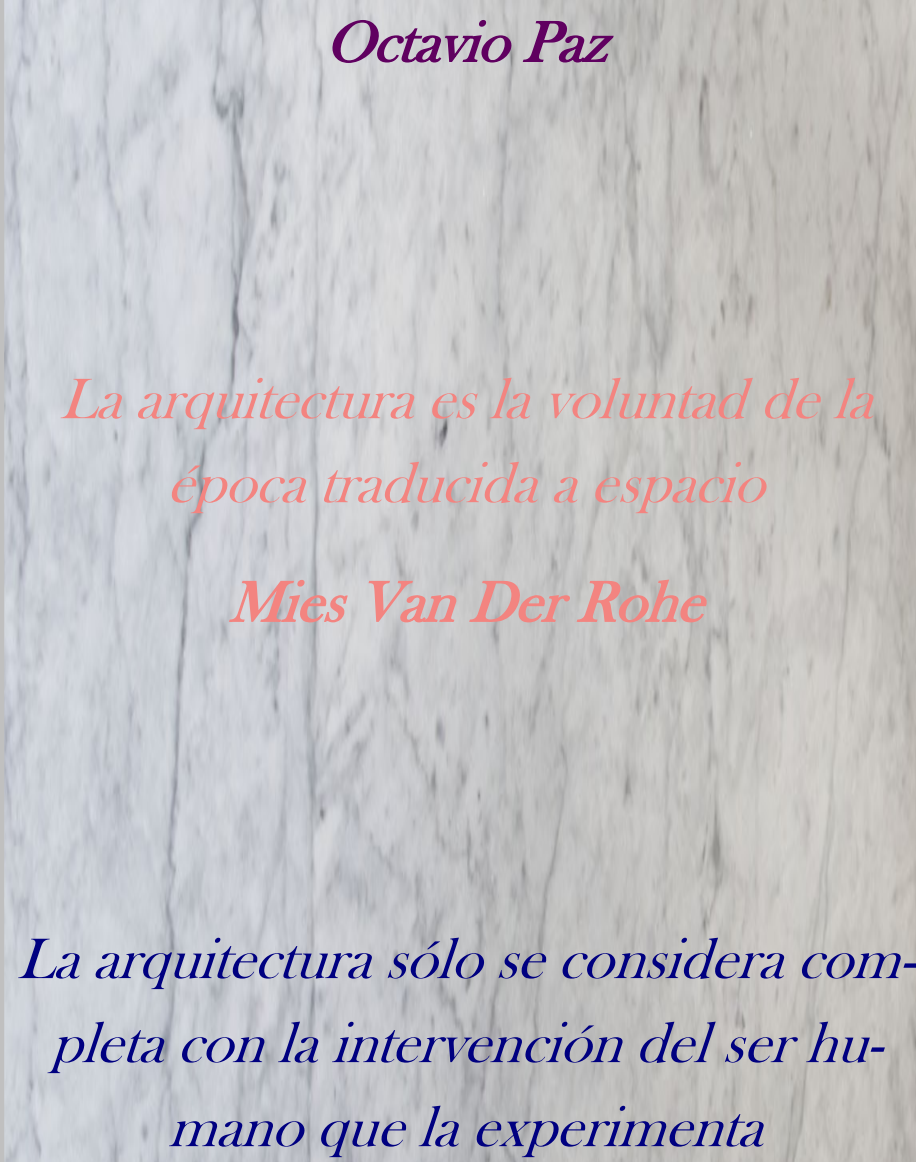

\section{Tadao Ando}

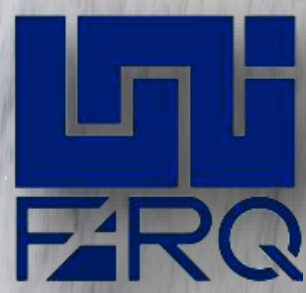

